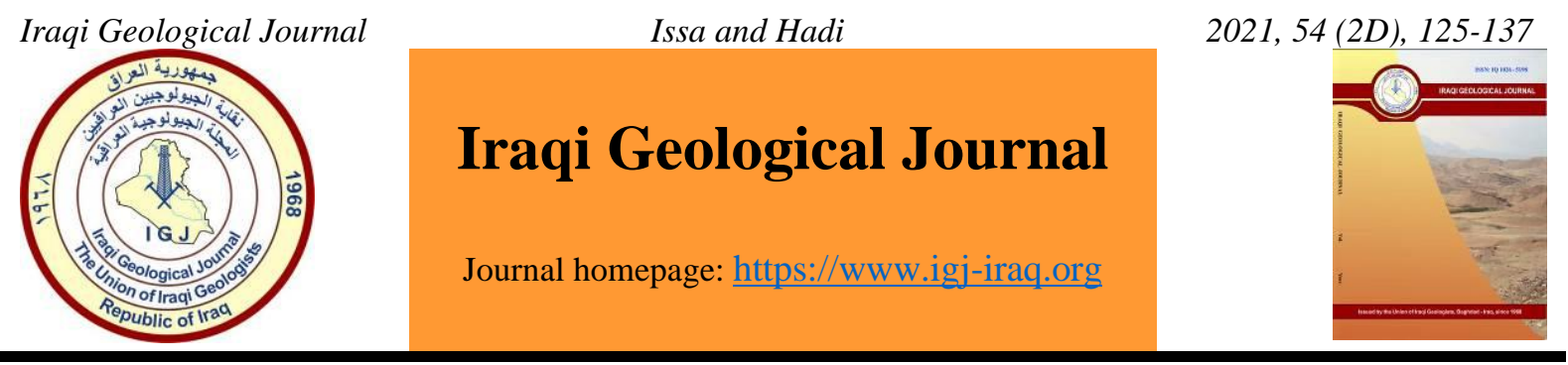

\title{
Estimation of Mechanical Rock Properties from Laboratory and Wireline Measurements for Sandstone Reservoirs
}

\author{
Mustafa Adil Issa ${ }^{1, *}$ and Farqad Ali Hadi ${ }^{1}$ \\ 1 Petroleum Engineering Department, College of Engineering, University of Baghdad, Baghdad, Iraq \\ * Correspondence: m.issa1908m@coeng.uobaghdad.edu.iq
}

Received: 13 June 2021; Accepted: 22 Juy 2021; Published: 31 October 2021

\begin{abstract}
Mechanical rock properties are essential to minimize many well problems during drilling and production operations. While these properties are crucial in designing optimum mud weights during drilling operations, they are also necessary to reduce the sanding risk during production operations. This study has been conducted on the Zubair sandstone reservoir, located in the south of Iraq. The primary purpose of this study is to develop a set of empirical correlations that can be used to estimate the mechanical rock properties of sandstone reservoirs. The correlations are established using laboratory (static) measurements and well logging (dynamic) data. The results support the evidence that porosity and sonic travel time are consistent indexes in determining the mechanical rock properties. Four correlations have been developed in this study which are static Young's modulus, uniaxial compressive strength, internal friction angle $\varphi$, and static Poisson's ratio $v$ with high performance capacity (determination coefficient of $0.79,0.91,0.73$, and 0.78 , respectively). Compared with previous correlations, the current local correlations are well-matched in determining the actual rock mechanical properties. Continuous profiles of borehole-rock mechanical properties of the upper sand unit are then constructed to predict the sand production risk. The ratio of shear modulus to bulk compressibility $(\mathrm{G} / \mathrm{Cb})$ as well as rock strength are being used as the threshold criterion to determine the sanding risks. The results showed that sanding risk or rock failure occurs when the rock strength is less than $7250 \mathrm{psi}(50 \mathrm{MPa})$ and the ratio of G/Cb is less than $0.8^{*} 10^{12} \mathrm{psi}^{2}$. This study presents a set of empirical correlations which are fewer effective costs for applications related to reservoir geomechanics.
\end{abstract}

Keywords: Rock mechanical properties; Unconfined compressive strength; Poisson's ratio; Young's modulus; Internal friction angle; Sand production

\section{Introduction}

Most rock mechanical properties are not directly measured at the wellbore; thus, it is essential to determine these properties using measurable core and well log data. This determination potentially minimizes many drilling and production challenges during the well life (Aziz \& Hussein, 2021). Accurate knowledge of the mechanical rock parameters is vital for several geo-mechanical applications, including but not limited to predicting the wellbore's stability and investigating the reservoir compaction during depletion of the reservoir (Woehrl et al., 2010). These properties are rock strength or uniaxial compressive strength, internal friction angle, and rock cohesion, as well as the rock elastic properties that involve Young's modulus, Poisson's ratio, and shear and bulk moduli. They are extensively utilized DOI: $\underline{10.46717 / \text { igj.54.2D.10Ms-2021-10-29 }}$ 
to predict in-situ stresses, wellbore stability analysis, the potential of sand production, reservoir compressibility survey, and determination of optimal drilling mud pressure (Chang et al., 2006; Geovany Moreno et al., 2017).

Many drilling and production challenges may be exposed throughout the reservoir life. Such problems are compaction of formation and sand production, which may happen after many years of production. These may cause a reduction in permeability and the pressure of the reservoir (Khamehchi $\&$ Reisi, 2015). To overcome these challenges, it is essential to determine the geomechanical parameters for any modelling process of the reservoir. However, static measurements of geomechanical parameters along the well profile are often limited due to the limited numbers of core samples for cost and timesaving purposes. Alternatively, these parameters can be directly measured from rock testing or indirectly measured from open-hole logging information such as density log and sonic log and rock testing. As a comparison with the dynamic indirect method, the direct (static) method can be considered as a more confident and ideal technique than the dynamic methods as well as they are widely accepted by the earth mechanics community worldwide to determine the mechanical rock properties using rock samples ( Zoback, 2007; Fjar et al., 2008; Najibi et al., 2015; Aadnoy \& Looyeh, 2019; Zhang, 2019).

Many empirical correlations have been reported in the literature to determine the rock mechanical characteristics using well log ( Ryshkewitch, 1953; Tixier et al., 1975; Sethi, 1981; Najibi et al., 2015; S. Zhang \& Abdelrahman, 2015). Weingarten and Perkins (1995) presented a relationship between porosity and internal friction angle for sandstone rocks taking from the Louisiana region Gulf of Mexico. Lacy (1997) then used 600 core samples to compute the static and dynamic rock mechanical properties using ultrasonic, uniaxial, and triaxial tests. Edimann et al. (1998) utilized the triaxial test on sandstone rocks taken from the North Sea fields to construct direct linear-empirical correlations between the rock mechanical properties and porosity. Bradford et al. (1998) used a triaxial test on core samples recovered from the Everest reservoir of the North Sea field to correlate the rock static and dynamic mechanical properties. For sandstone formation in Fulla oil field, south of Sudan, Zhang \& Abdelrahman (2015) presented a study to construct correlations between mechanical rock properties and porosity. As a result, many correlations have been established to determine the mechanical properties of different formation lithologies using other measurable well logs.

A field case has been conducted in this study to correlate the mechanical rock properties with other petrophysical properties using core and well log data. The Zubair sandstone, located in southern Iraq, is the most critical hydrocarbon reservoir where the mechanical rock properties are not profoundly studied. A comparison with previous correlations in literature has also been performed to test whether an improvement in determining the mechanical rock properties is achieved in this study. Sanding risk at the upper unit of Zubair reservoir is also checked based on the continuous profiles of the mechanical rock properties.

\section{Area of Study}

The Zubair reservoir has been conducted in this study to generate a set of empirical correlations that can be used to determine the mechanical rock properties using other measurable rock properties. The Zubair reservoir, which belongs to the lower cretaceous age, primarily consists of interrelated sandstones and shales with a few limestones and siltstones. The Zubair reservoir can be considered as the most critical reservoir in southern Iraq. It is characterized by the Shuaiba layer in the top and the Ratawi strata in the bottom. The gross thickness of Zubair reservoir is about $450 \mathrm{~m}$. This reservoir is normally divided into five units dependent on the sand/shale ratio: upper shale, upper sand, middle shale, lower sand, and lower shale. All hydrocarbons production comes from the upper sand zone and the fourth pay zone (lower sand) ( Al-Jafar \& Al-Jaberi, 2019). 
In this study, the continuous profile of the mechanical rock properties along the upper sand unit of the Zubair reservoir area of interest is constructed, relying on the developed correlations and calibrating with the laboratory measurements.

\section{Materials and Methods}

The adopted methodology in this study is detailed in Fig. 1, which can be summarized in the following steps:

- Collect and audit the required wells data from the field of interest.

- Develop a set of empirical correlations that can be utilized to estimate the mechanical rock properties (i.e., rock strength and elastic parameters) of sandstone reservoirs by using the Alternating Conditional Expectations (ACE) technique and Statistica Program version 5.5.

- Comparison of the developed correlations with literature based on two error-based metrics (the root means square error (RMSE) and the absolute relative average difference (ARAD)) and on the histograms of misfits was utilized rely on Statistica Program.

- Implementation of these correlations to construct the profiles of mechanical rock properties along with Zubair formation using Techlog software version 2015.3.

- Apply these correlations in one geomechanical application, i.e., sand production potential based on the threshold of two criteria: the ratio of shear modulus to bulk compressibility $(\mathrm{G} / \mathrm{Cb})$ and unconfined compressive strength (UCS) criteria.

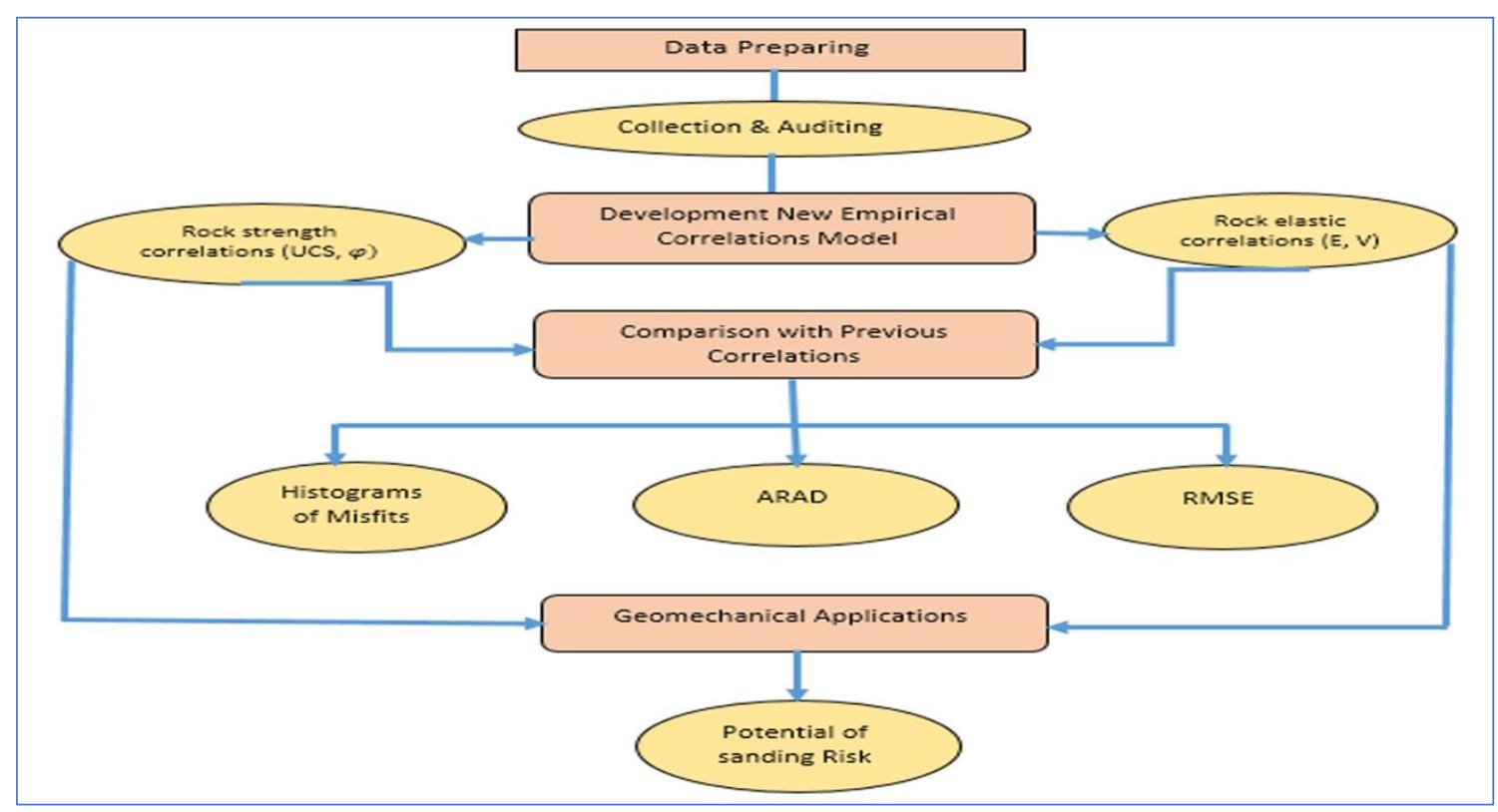

Fig. 1. Shows the workflow of this study

\section{Development of New Models}

Data of triaxial tests were used in this study to obtain empirical correlations of Zubair reservoir which can be locally used to further determination of the reservoir rock properties. An unconfined compressive stress (UCS), Young's modulus (E), static Poisson ratio (v), porosity (Ø), and internal friction angle $(\varphi)$ were determined from rock samples taking from the Zubair Formation. This paper presents the workflow and the relationships derived from each mechanical parameter's layout versus porosity or other elastic parameters.

Log records have been readjusted to values measured from the rock core samples to accurately detect the profiles of rock strength and elastic properties. The result is a continuous profile of each 
mechanical property that can be used for applications related to geomechanics such as wellbore stability analysis and sand production. Previous correlations published in the literature were used to verify and validate the developed correlations in the current study. Table 1 lists many of published correlations in literature with their performance ability using the correlation coefficient criteria $\left(\mathrm{R}^{2}\right)$. Three error-based metrics, including the determination coefficient $\left(\mathrm{R}^{2}\right)$, the root mean square error (RMSE), and the absolute relative average difference (ARAD) were found for each developed model.

Table 1. Previous correlation of mechanical properties in sandstone formation

\begin{tabular}{llcl}
\hline Eq. no. & Equation & $\boldsymbol{R}^{\mathbf{2}}$ & Reference \\
\hline 1 & $E_{d}=0.2652 V_{p}^{2.04}$ & 0.9 & Lacy (1997) \\
2 & $E_{S}=0.0293 E_{d}^{2}+0.4533 E_{d}$ & 0.73 & Lacy (1997) \\
3 & $E_{S}=0.0018 E_{d}^{2.7}$ & - & Bradford et al. (1998) \\
4 & UCS $=2.28+4.1089 E_{S}$ & - & Bradford et al. (1998) \\
5 & $U C S=0.2787 E_{S}^{2}+2.4582 E_{S}$ & 0.84 & Lacy (1997) \\
6 & $\varphi=64.369-99.238 \emptyset$ & 0.75 & Abbas et al. ( 2018) \\
7 & $\varphi=-0.7779 \emptyset+41.929$ & 0.71 & Edimann et al. (1998) \\
8 & $\varphi=57.8-105 \emptyset$ & - & Weingarten \& Perkins (1995) \\
9 & $v=0.1203-0.766 \emptyset$ & 0.7 & Abbas et al. ( 2018) \\
10 & $v=1.1148 \emptyset+0.1356$ & 0.77 & S. Zhang \& Abdelrahman (2015) \\
11 & $v=0.0052 \emptyset+0.0508$ & 0.64 & Edimann et al. (1998) \\
\hline
\end{tabular}

\subsection{Rock Strength Parameters}

Fig. 2 lists the results of uniaxial compressive tests of core samples that have been taken from the Zubair sandstone reservoir. The results are unconfined compressive strength (UCS) and static Young's modulus (Es). The results reveal a positive trend between UCS and Es. This means that increasing the rock stiffness will increase its strength and vice versa. Table 2 illustrates the developed correlation (Eq. 14) with high-performance capacity $\left(R^{2}\right.$ of 0.91$)$, which can be used to estimate the strength of sandstone based on its stiffness ( static Young's modulus).

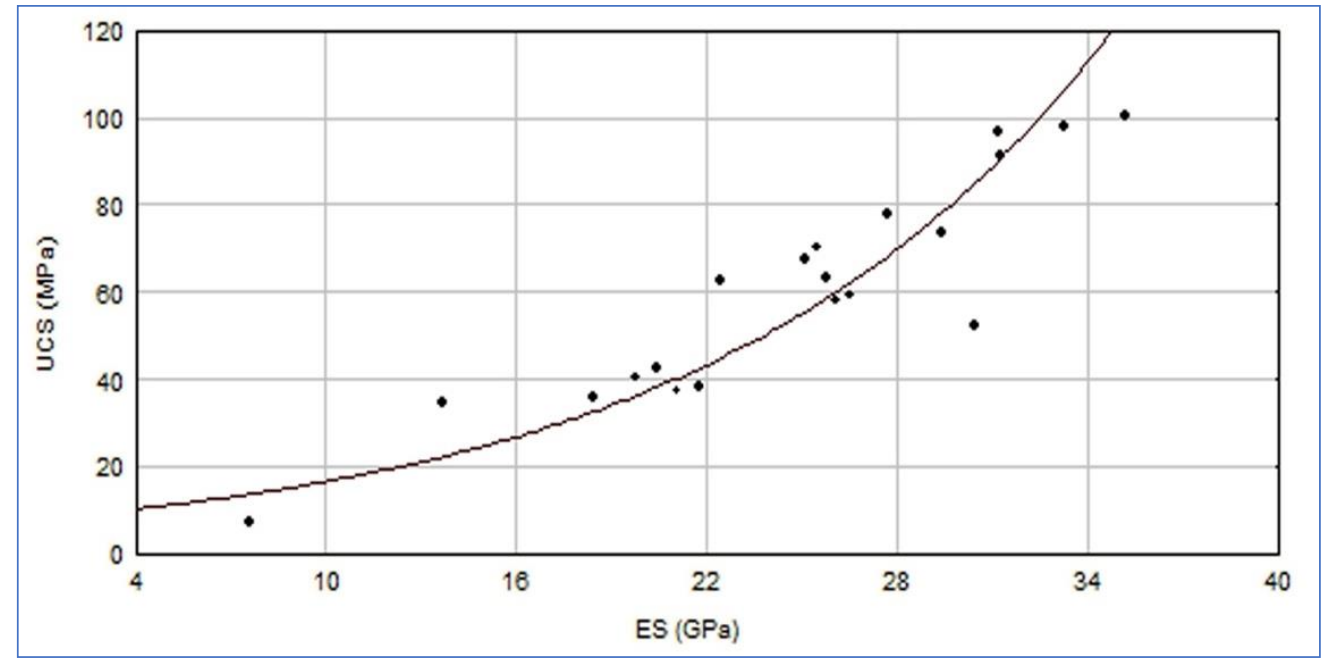

Fig. 2. Uniaxial Compressive Strength (UCS) versus static elastic modulus (Es). 
Table 2. Correlations of rock mechanical properties of the Zubair sandstone.

\begin{tabular}{lll}
\hline Eq. no & Equation & $\boldsymbol{R}^{\mathbf{2}}$ \\
\hline 12 & $E_{d}=107831 \Delta t^{-1.903}$ & 0.99 \\
13 & $E_{S}=-0.02 E_{d}^{2}+2.1356 E_{d}-25.296$ & 0.79 \\
14 & $U C S=0.3348 E_{S}^{1.6081}$ & 0.91 \\
15 & $\emptyset_{C}=32.252 \emptyset^{2}+6.0753 \emptyset-1.7603$ & 0.73 \\
& $\varphi=-0.23519 \emptyset c^{2}+4.4937 \emptyset c+45.182$ & \\
16 & $v=1.199 \emptyset^{0.8149}$ & 0.78 \\
\hline
\end{tabular}

Where: $\varnothing \mathrm{c}$ is the transformation porosity; $\varnothing$ is the porosity that obtained from wireline logging. Fig. 3 shows the values of the internal friction angle $(\varphi)$ based on the triaxial compressive tests of the Zubair core samples. These values are correlated with porosity (Eq. 15), obtaining $\mathrm{R}^{2}$ of 0.73 . The scatter in the data around the fit curve in Fig. 3 can be attributed to specimen heterogeneities and restricted laboratory errors. This means that assuming $\varphi$ in many applications related to the sandstone geomechanics may carry out a huge uncertainty in the output function. This shows the importance of the local use of the presented correlation (Eq. 15) to estimate the internal friction angle of sandstone reservoirs in the southern Iraqi oil field. If it is used out of the area of interest, it must be calibrated with actual data measurements of the rock internal friction angle.

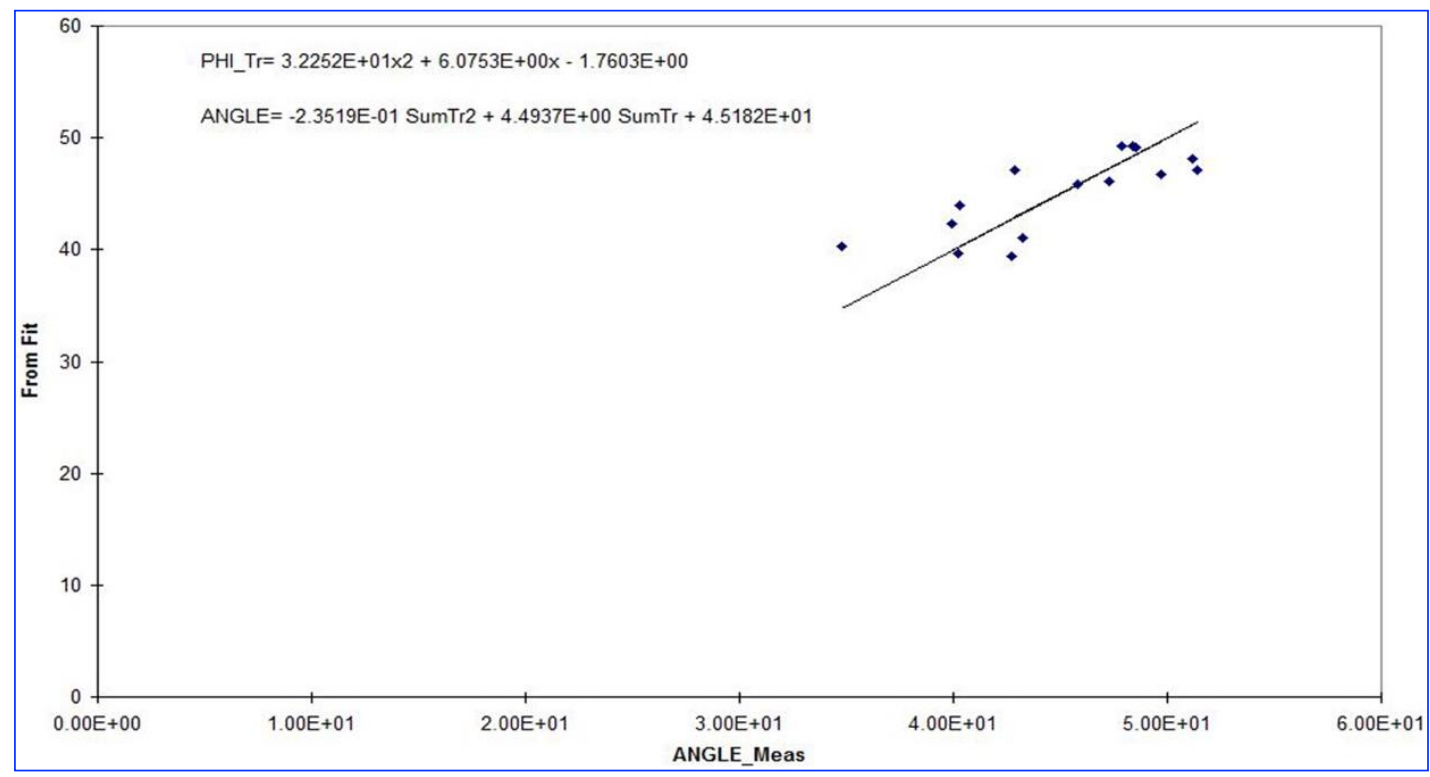

Fig. 3. Optimal transformation for dependent and independent variable and final correlation by Alternating Conditional Expectations (ACE) technique.

\subsection{Elastic Parameters}

Table 2, along with Figs. 4 and 5 present the developed correlations between the static Young's modulus (Es) and the dynamic Young's modulus (Ed), and between Poisson's ratio (v) and porosity (Eqs. 13 and 16, respectively). The obtaining $\mathrm{R}^{2}$ are 0.79 and 0.78 , respectively. It should be mentioned that the dynamic Young's modulus has been calculated based as a function of the rock shear modulus and Poisson's ratio. In other words, as depicted in equation 12, the dynamic Young's modulus data points 
were calculated from data points of dynamic shear modulus and Poisson's ratio, then correlated with sonic compressive wave points. The results of this section showed that both of the Es and $v$ have positive trend lines with the independent parameters.

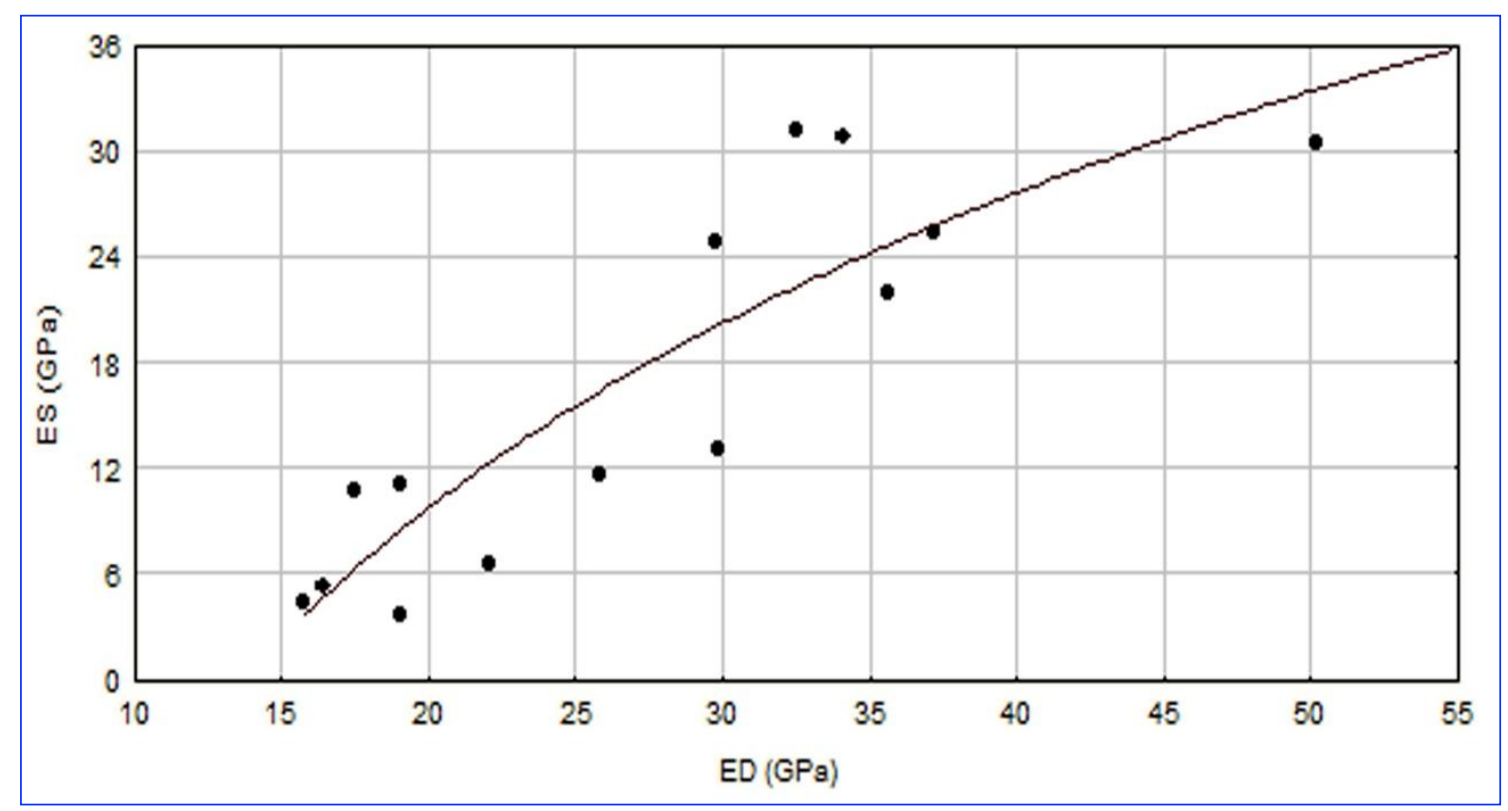

Fig. 4. Correlation between static Young's modulus (Es) and dynamic Young modulus $\left(\mathrm{E}_{\mathrm{d}}\right)$

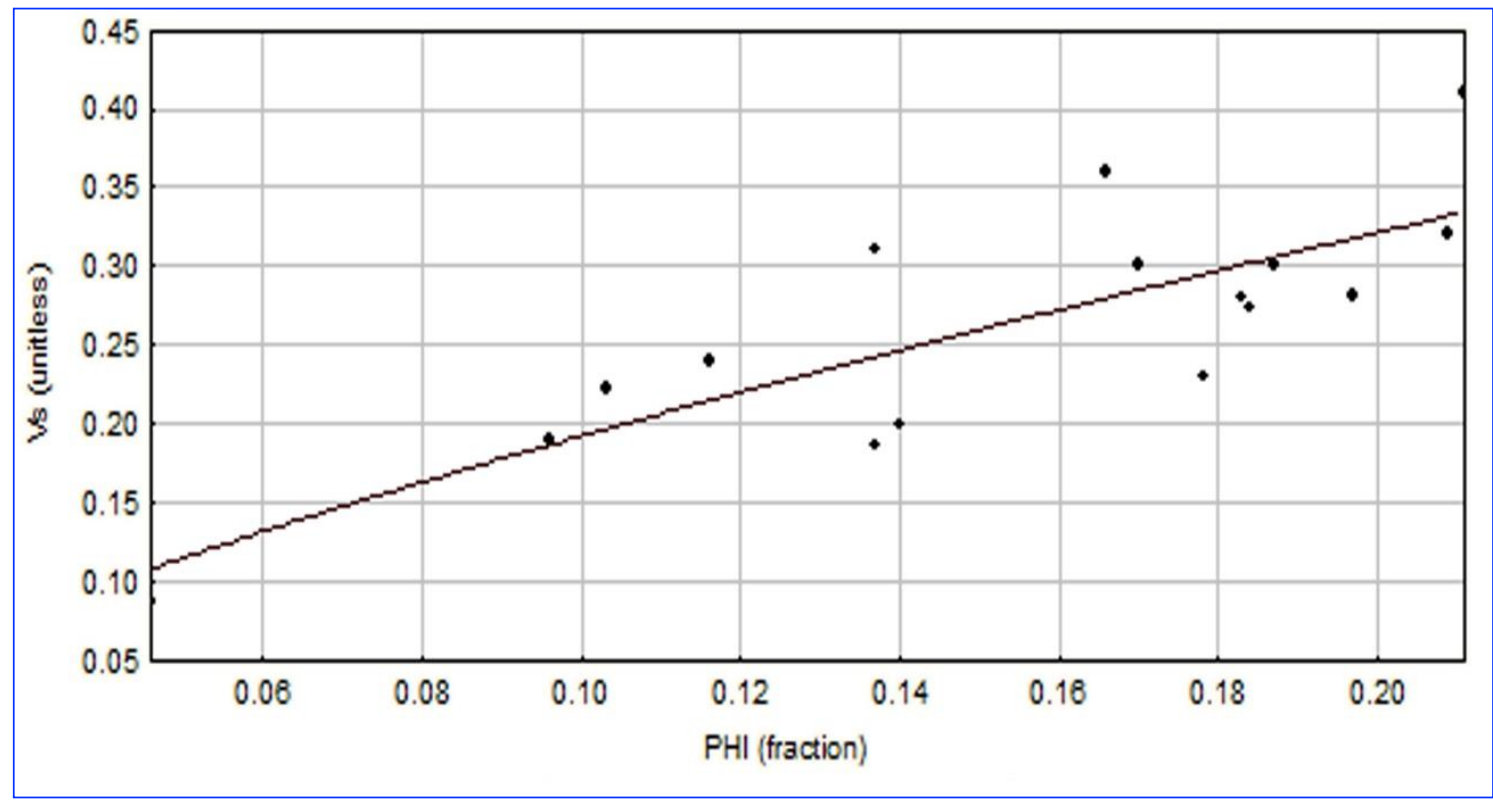

Fig. 5. Correlation of Poisson's ratio with porosity.

\subsection{Comparison of the Developed Correlations with Literature}

It is essential to compare the developed correlations in this study with literature for further determination of mechanical rock properties. The performance of the developed correlations in Table 2 has been conducted and compared with the previous correlations in Table 1 based on the data of the Zubair Formation. Two approaches have made the comparison in this study. The first approach is based on two error-based metrics, which are the root mean square error (RMSE) (Eq. 17) and the absolute 
relative average difference (ARAD) (Eq. 18), where $\mathrm{Yi}$ is the estimated value, $\mathrm{Xi}$ is the measured core value, and $n$ is the number of measured core values. The second approach is based on calculating the difference between the estimated and the actual values for each mechanical rock property.

$$
\begin{gathered}
\text { RMSE }=\sqrt{\frac{\sum\left(X_{i}-Y_{i}\right)^{2}}{n}} \\
A R A D=\frac{\sum \|\left(X_{i}-Y_{i}\right) \mid \cdot \frac{100}{X_{i}}}{n}
\end{gathered}
$$

\subsubsection{Comparison based on two error-based metrics}

Table 3 presents a comparison between the developed and previous correlations based on the two error-based criteria (RMSE and ARAD). Accordingly, the results revealed that all of the developed correlations have shown lowest values of RMSE and ARAD than previous correlations. This proves the possibility of using the developed correlations in creating the profiles of rock mechanical properties with less uncertainties in many applications related to reservoir geomechanics.

Table 3. Comparison between the results of the developed correlations with previous correlations

\begin{tabular}{lccc}
\hline Empirical Correlation & Description & RMSE & ARAD \% \\
\hline Eq. 1 & & & \\
Eq. 12 & $E_{d}$ vs $\Delta t$ & 3.287 & 9.219 \\
& & 1.335 & 3.438 \\
Eq. 2 & & & \\
Eq. 3 & Es vs Ed & 5.679 & 44.182 \\
Eq. 13 & & 11.806 & 38.031 \\
& & 4.67 & 36.182 \\
Eq. 4 & UCS vs Es & 44.37 & 93.92 \\
Eq. 5 & & 65.079 & 99.999 \\
Eq. 14 & & 9.446 & 13.359 \\
& & & \\
Eq. 6 & & 10.14 & 19.658 \\
Eq. 7 & $\varphi$ vs $\emptyset$ & 16.939 & 31.658 \\
Eq. 8 & & 9.951 & 20.422 \\
Eq. 15 & & 2.877 & 5.514 \\
& & & \\
Eq. 9 & & 0.279 & 93.514 \\
Eq. 10 & & 0.064 & 28.252 \\
Eq. 11 & & 0.223 & 77.688 \\
Eq. 16 & & 0.044 & 14.514 \\
\hline
\end{tabular}

\subsubsection{Comparison based on histograms of misfits}

This section represents another comparison between the developed and previous correlations using the misfit histograms (uncertainty). These histograms have shown the difference between the core derived data and the predicted data for each mechanical rock property. (Figs. 6, 7, 8, and 9) present the results of the developed correlations for static Young's modulus (Eq. 13), unconfined compressive strength (Eq. 14), internal friction angle (Eq. 15), and Poisson's ratio (Eq. 16), respectively. 
Fig.6 displays the histogram of the misfits between Eq. 13 and two previous correlations (Eqs. 2 and 3). The results showed that Eq. 13 is fitting $50 \%$ of the static Young's modulus (laboratory data) within $\pm 2 \mathrm{GPa}$, while Eqs. 2 and 3 are fitting $21.4 \%$ and $35.7 \%$ within $\pm 2 \mathrm{GPa}$, respectively. The performance of Eq. 13 will be decreased with increasing uncertainty (increasing the difference between the estimated and measured static Young's modulus). These misfit data revealed that Eq. 13 tends to be accurate in determining the static Young's modulus within \pm 2 GPa uncertainty.

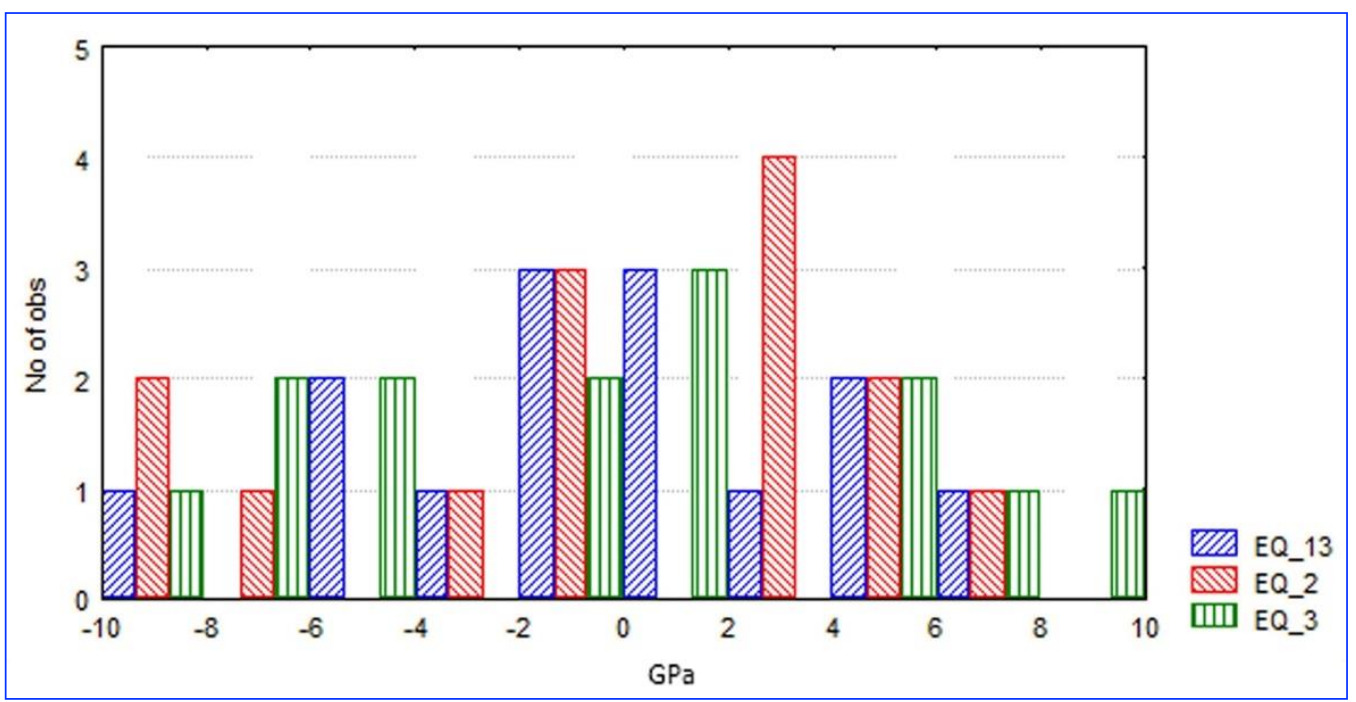

Fig. 6. Histogram of estimated - measured static Young's modulus (Es E-Es M).

With respect to the unconfined compressive strength (UCS), Fig. 7 shows the difference between Eq. 14 and other previous correlations (Eqs. 4 and 5). The histogram of misfits indicated that Eq. 14 is fitting $60 \%$ of the laboratory-measured data within uncertainty of $\pm 5 \% \mathrm{MPa}$, while Eqs. (4 and 5) are fitting $0 \%$ and $0 \%$ within $\pm 5 \mathrm{MPa}$, respectively. While Eq. 4 gave overestimation of UCS within +32 $\mathrm{MPa}\left(\mathrm{UCS}_{\mathrm{E}}-\mathrm{USC}_{\mathrm{M}}\right.$ is positive), Eq. 5 gave underestimation of UCS within $-17 \mathrm{MPa}\left(\mathrm{UCS}_{\mathrm{E}}-\mathrm{USC}_{\mathrm{M}}\right.$ is negative). These results showed the possibility of using Eq. 14 in determining the strength of sandstone rocks with less uncertainties (Fig. 7).

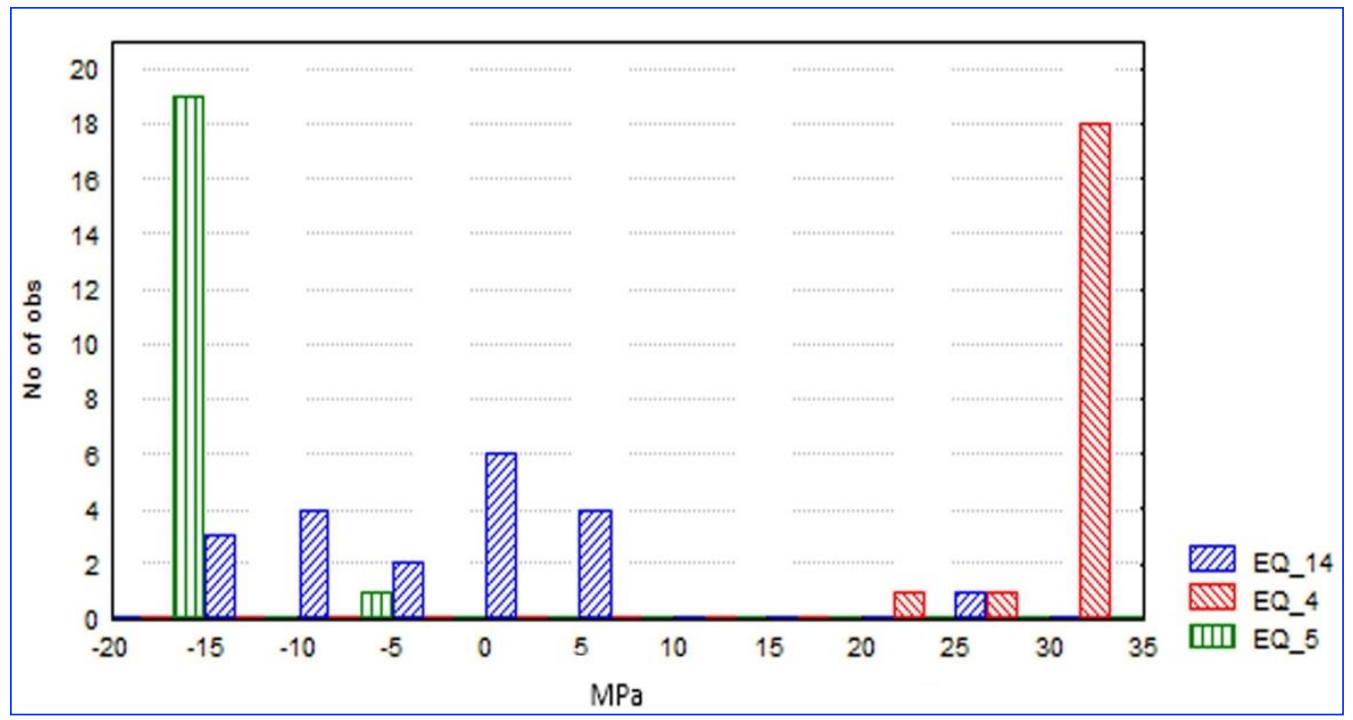

Fig.7. Histogram of estimated - measured Uniaxial Compressive Stress $\left(\mathrm{UCS}_{\mathrm{E}}-\mathrm{USC}_{\mathrm{M}}\right)$. 
The histogram of misfits in Fig. 8 showed that Eq. 15 which estimates the internal friction angle of sandstone rocks is fitting $67 \%$ of the internal friction angle ( $\varphi$-laboratory data) within $\pm 3 \mathrm{deg}$, while Eqs. 6,7 , and 8 are fitting $20 \%, 7 \%$ and $7 \%$ of ( $\varphi$-laboratory data) within $\pm 3 \mathrm{deg}$. The performance of the developed equation (Eq. 15) appears to still have a smaller uncertainty in determining the internal friction angles of sandstone rocks. In contrast, increasing the misfit or uncertainty will reduce the accuracy of previous correlations in determining $(\varphi)$.

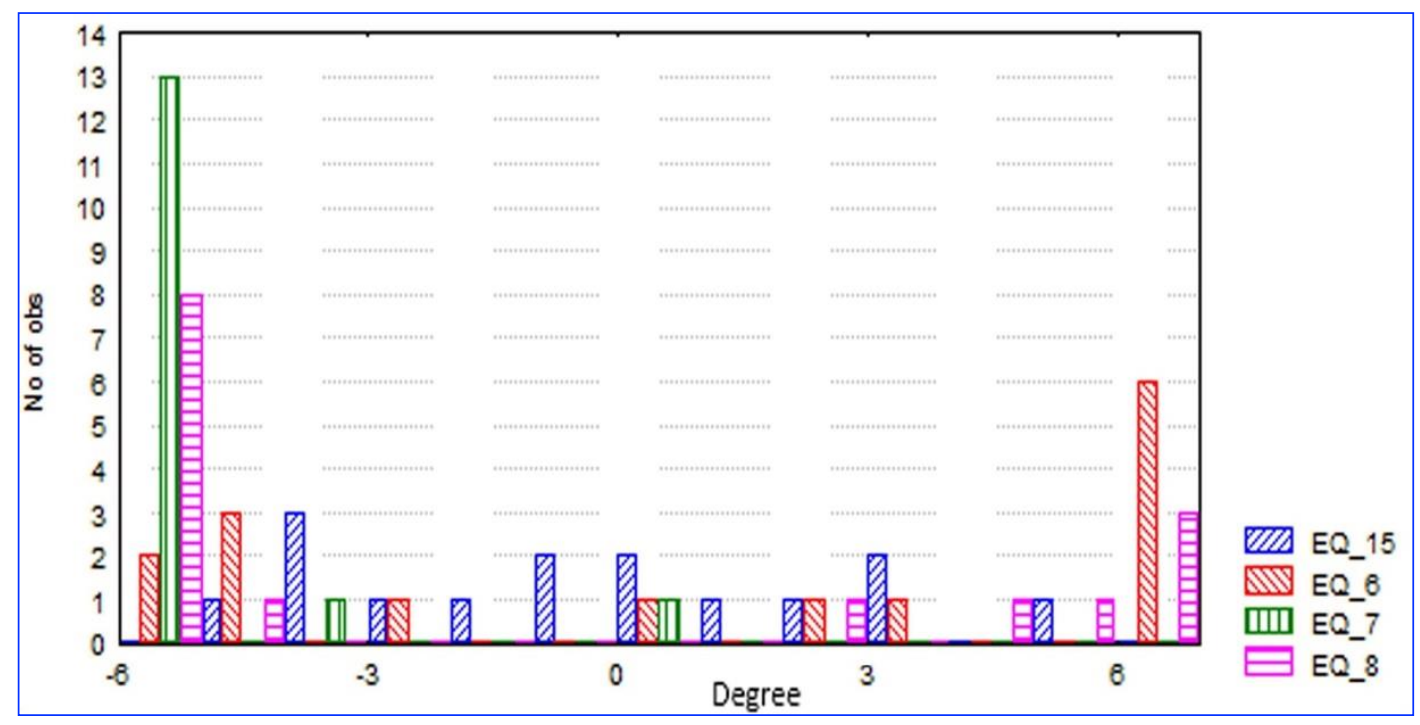

Fig. 8. Histogram of estimated - measured friction angle $\left(\varphi_{E}-\varphi_{M}\right)$.

In Fig. 9, the developed correlation (Eq. 16) is compared with previous correlations (Eqs. 9, 10, and 11) for determining the static Poisson's ratio. A $69 \%$ of fitting is observed by Eq. 16 within \pm 0.04 of uncertainty in the static Poisson's ratio. In contrast, Equations 9, 10, and 11 are fitting of $6.25 \%$, $37.5 \%$ and $6.25 \%$ within \pm 0.04 uncertainty of static Poisson's ratio, respectively. , equations 9 and 11 reveal an over-estimate of Poisson's ratio.

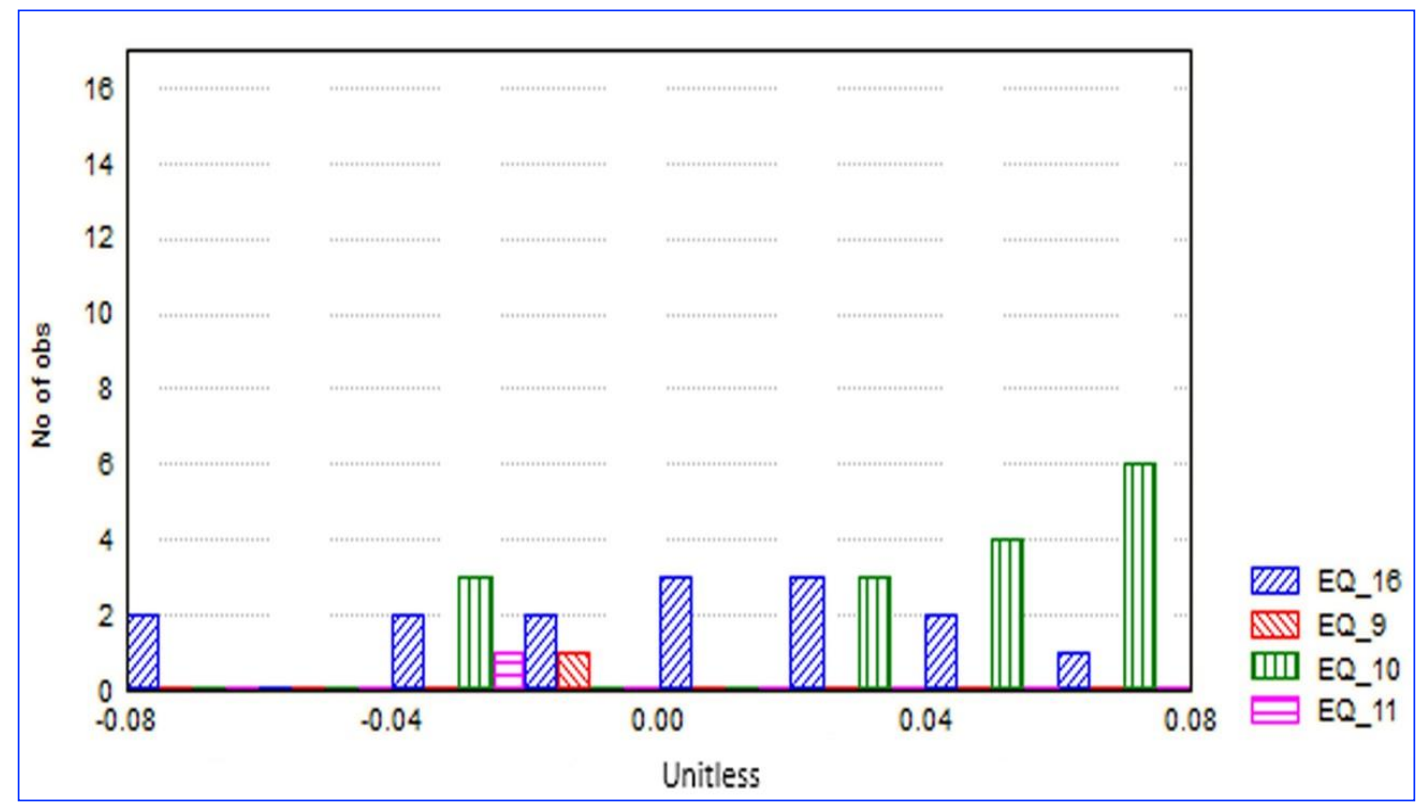

Fig. 9. Histogram of estimated - measured Poissan's ratio $\left(\mathrm{v}_{\mathrm{E}}^{-} \mathrm{v}_{\mathrm{M}}\right)$ 


\subsection{Correlations Implementation in Constructing the Rock Mechanical Properties}

The correlations that have been developed in this study were utilized to determine the mechanical rock properties from porosity logs for applications related to geomechanics. Each rock mechanical property was plotted versus depth (along with the Zubair Formation). The measured lab data of rock mechanical parameters were added to the continuous profile for calibration. Fig.10 shows a high compatibility between the calculated and the lab measurements of all rock mechanical properties [internal friction angle (FANG), unconfined compressive strength (UCS), tensile strength (TSTR is function of UCS), Poisson's ratio (PR), and Young's modulus (YME)].

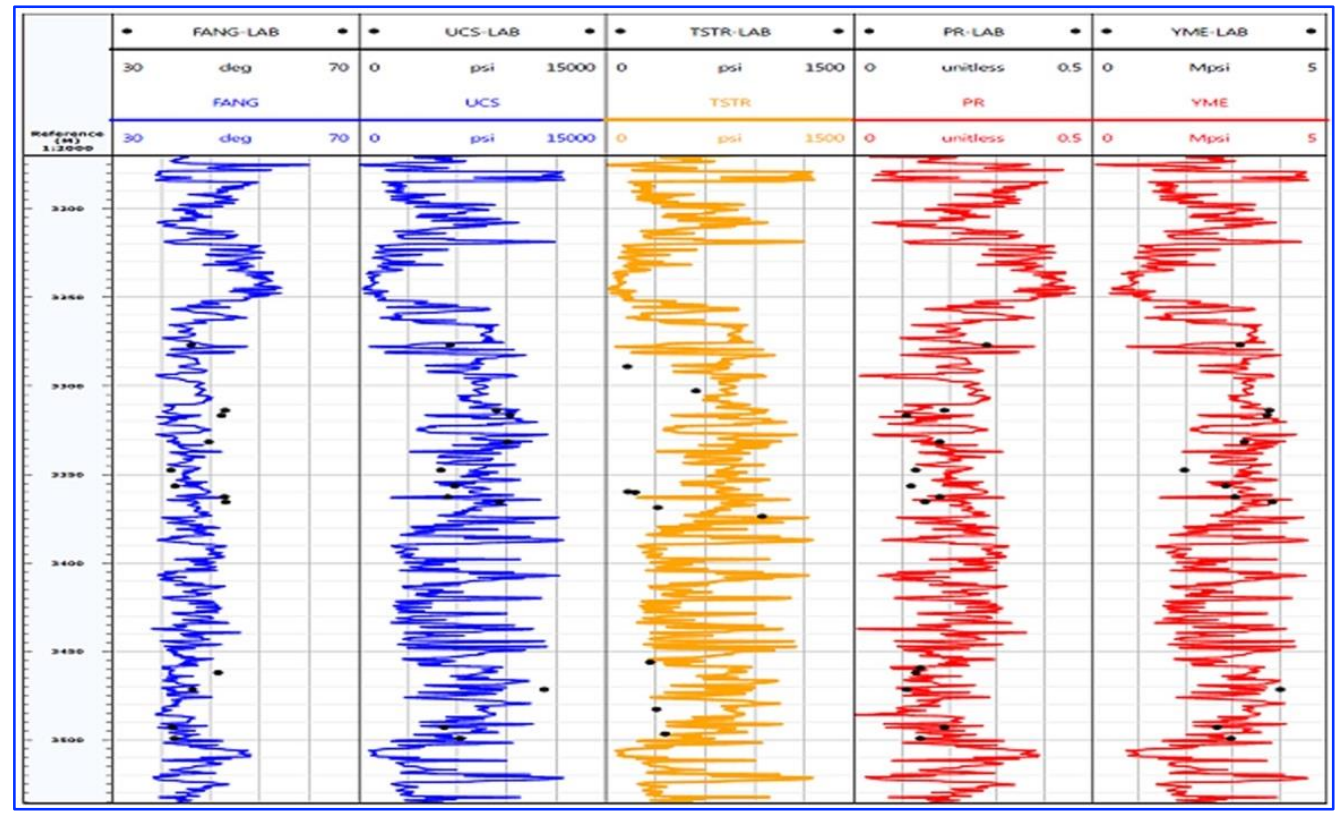

Fig. 10. Well profile of geomechanical properties for Zubair Formation

\subsection{Applications of Developed Correlations in a Field Study}

The outcome of this study is by developing new correlations to estimate the mechanical rock properties for the upper and lower sand units of the Zubair reservoir for many applications related to geomechanics, including wellbore stability analysis, sand production, and fault reactivation. In other words, the constructed continuous profiles can be utilized in designing and fulfilment of drilling and production operations along with the Zubair Formation. Sand production, as an important application in unconsolidated reservoirs, has become a cause of concern for production engineers. It can be recognized as a serious problem in the wells that producing from the sand formation. This problem cause corrosion of the tubing, casing, surface facilities, linear, as well as tubing buckling due to the influx of sand (Khamehchi \& Reisi, 2015). In this study, the potential of the sanding risk through Zubair Formation can be determined using two criteria: the ratio of shear modulus to the bulk compressibility $(\mathrm{G} / \mathrm{Cb})$ and the unconfined compressive strength (UCS) criteria.

\subsubsection{The Ratio of Shear Modulus to Bulk Compressibility Criterion}

Tixier et al. (1975) proposed an empirical correlation that suggests a threshold for sanding. This method involves the ratio of shear modulus to bulk compressibility $(\mathrm{G} / \mathrm{Cb})$ as an indicator in determining the sanding risk. This ratio implied that a $0.8 * 10^{12} \mathrm{psi}^{2}\left(38 \mathrm{MPa}^{2}\right)$ is a threshold for sanding existed. If the ratio of $\mathrm{G} / \mathrm{Cb}$ is below $0.8^{*} 10^{12} \mathrm{psi}^{2}$, sand production will occur. 


\subsubsection{Uniaxial compressive strength (UCS) criteria}

Production of reservoir fluids is associated with depletion of reservoir pressure, and the drawdown pressure is directly related to the rock strength (Edimann et al., 1998). If the drawdown pressure overcomes the unconfined compressive strength, the breakout or the collapsing in sandstone formation will take place (Bratli \& Risnes, 1981). If the unconfined compressive strength is below 7250 psi as a threshold, sand production is likely to be occurred (Edimann et al., 1998). The bulk compressibility and shear modulus were derived utilizing equations 19 and 20 respectively (Aadnoy \& Looyeh, 2019; Wu et al., 2010), where $E$ is Young's modulus and $v$ is a Poisson's ratio.

$$
\begin{aligned}
& C_{b}=\frac{3(1-2 v)}{E} \\
& G=\frac{E}{2(1+v)}
\end{aligned}
$$

As mentioned previously, the upper sand zone represents the main producing zone of Zubair Formation. Fig.11 illustrates the sand production prediction for the upper sand interval of Zubair formation based on thresholds of G/Cb and UCS criteria. It is important to mention that the mechanical properties of the Zubair Formation have been established based on the developed correlations in this study. Considering the threshold of Tixier et al. (1975) where the ratio of $G / C b$ is in $10^{12} \mathrm{psi}^{2}$, a reference line has been drawn for the upper sand unit (Fig. 11). The results showed that there is an expected risk of sand potential at different intervals of the upper sand unit of Zubair reservoir (yellow-colored) (e.g., 3290 and $3370 \mathrm{~m} \mathrm{MD)}$ ). According to the practical study of Edimann et al. (1998), a threshold of 7250 psi $(50 \mathrm{MPa})$ of UCS is highlighting in Fig 11. It can be seen that there is an expected potential of sanding at different intervals of the upper sand zone (e.g., 3300 and $3370 \mathrm{~m} \mathrm{MD).} \mathrm{Another} \mathrm{important}$ point can be concluded from Fig. 11 is that both the ratio of G/Cb and UCS criteria are similar in detecting the sanding potential zones. Considering from this Figure we can see the $G / C b$ and $U C S$ have the same behavior, and approximately all intervals of upper sand formation have a potential of sanding.

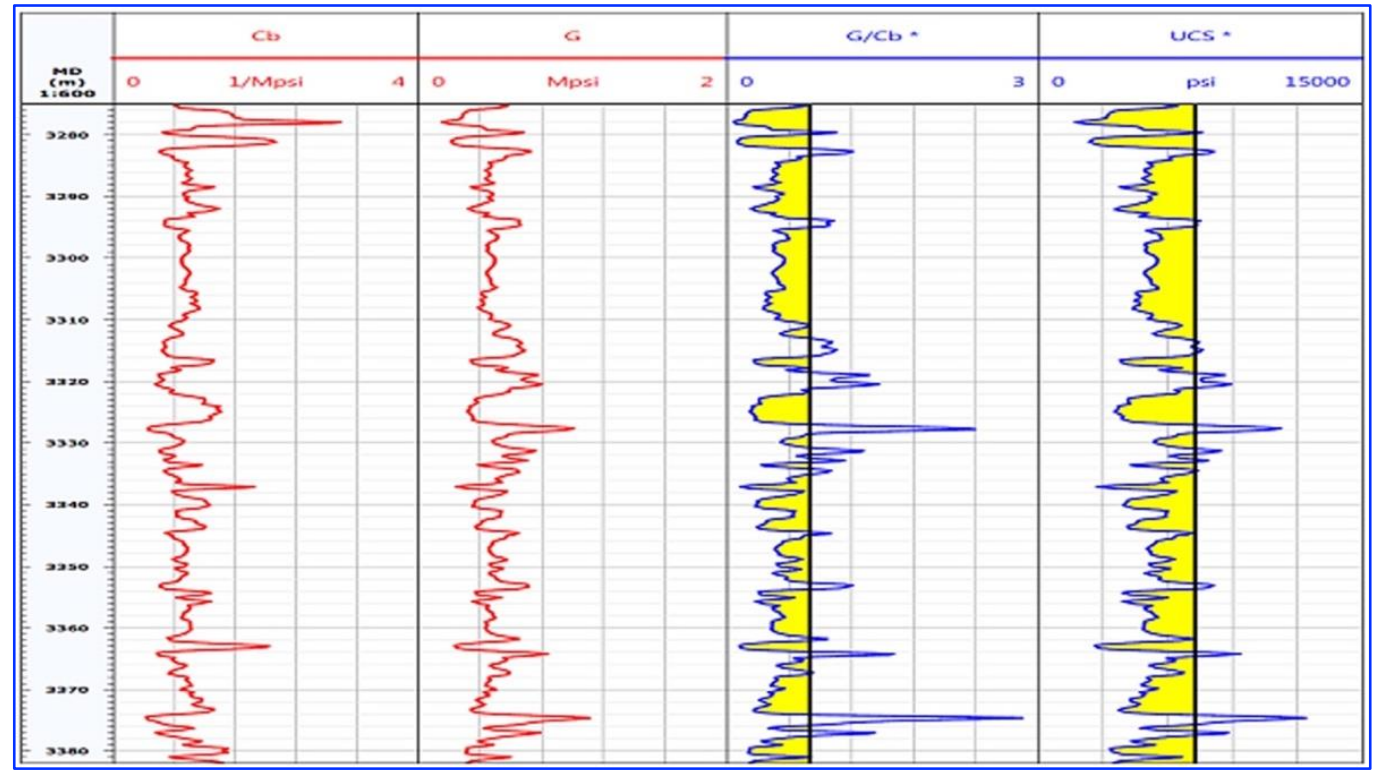

Fig. 11. Sand production prediction for upper sand formation

\section{Conclusions}

The conclusion of this study can be summarized by the following points: 
- A set of empirical correlations have been developed to estimate the rock mechanical properties of sandstone reservoirs based on laboratory and well log data.

- Porosity and sonic travel time are consistent indexes for determining the rock mechanical properties.

- Four correlations have been developed in this study which are static Young's modulus (Es), uniaxial compressive strength (UCS), internal friction angle $(\varphi)$, and static Poisson's ratio $(v)$ with high correlation coefficient $\left(\mathrm{R}^{2}\right)$, i.e., $0.79,0.91,0.73$, and 0.78 , respectively.

- The developed correlations are well matched with actual data in determining the rock mechanical properties with high performance capacity (high $\mathrm{R}^{2}$ ).

- A comparison with literature showed that the developed correlations are more conservative than previous correlations in estimating the rock mechanical properties with small RMSE and low percent of ARAD.

- Continuous profiles of rock mechanical properties have been established based on the developed correlations.

- The results show that sanding or rock failure occurs when the rock strength is less than 7250 psi (50 MPa) and the ratio of $G / C b$ is less than $0.8 * 10^{12} \mathrm{psi}^{2}\left(38 \mathrm{MPa}^{2}\right)$.

- The results show a possibility of sanding risks at different intervals of the upper sand unit of the Zubair reservoir.

\section{Acknowledgements}

The authors would like to thank Dr Oun Al-iedani and Mr. Ali Nooruldeen Abdulkareem for their assistance in editing the manuscript. The authors are very grateful to the Editor in Chief Prof. Dr. Salih M. Awadh, the Secretary of Journal Mr. Samir R. Hijab. and the Technical Editors for their great efforts and valuable comments.

\section{References}

Aadnoy, B., \& Looyeh, R., 2019. Petroleum rock mechanics: drilling operations and well design. Gulf Professional Publishing.

Abbas, A. K., Flori, R. E., Alsaba, M., Dahm, H., \& Alkamil, E. H. K., 2018. Integrated approach using core analysis and wireline measurement to estimate rock mechanical properties of the Zubair Reservoir, Southern Iraq. Journal of Petroleum Science and Engineering, 166, 406-419.

Al-Jafar, M. K., \& Al-Jaberi, M. H., 2019. Well logging and electrofacies of Zubair Formation for upper sandstone member in Zubair oil field, southern Iraq. Iraqi Geological Journal, 101-124.

Aziz, Q. A. A., \& Hussein, H. A., 2021. Mechanical rock properties estimation for carbonate reservoir using laboratory measurement: A case study from Jeribe, Khasib and Mishrif Formations in Fauqi Oil Field. Iraqi Geological Journal, 88-102.

Bradford, I. D. R., Fuller, J., Thompson, P. J., \& Walsgrove, T. R., 1998. Benefits of assessing the solids production risk in a North Sea reservoir using elastoplastic modelling. SPE/ISRM Rock Mechanics in Petroleum Engineering.

Bratli, R. K., \& Risnes, R., 1981. Stability and failure of sand arches. Society of Petroleum Engineers Journal, 21(02), 236-248.

Chang, C., Zoback, M. D., \& Khaksar, A., 2006. Empirical relations between rock strength and physical properties in sedimentary rocks. Journal of Petroleum Science and Engineering, 51(3-4), 223-237.

Edimann, K., Somerville, J. M., Smart, B. G. D., Hamilton, S. A., \& Crawford, B. R., 1998. Predicting rock mechanical properties from wireline porosities. SPE/ISRM Rock Mechanics in Petroleum Engineering.

Fjar, E., Holt, R. M., Raaen, A. M., \& Horsrud, P., 2008. Petroleum related rock mechanics. Elsevier.

Geovany Moreno, F., Guizada, P., Azly Abdul Aziz, A., \& Khanferi, R. N., 2017. Application of Critical Drawdown Pressure Prediction in Completion Design to Minimize Sanding in a Clastic Gas Reservoir in Saudi Arabia. SPE Kingdom of Saudi Arabia Annual Technical Symposium and Exhibition. 
Khamehchi, E., \& Reisi, E., 2015. Sand production prediction using ratio of shear modulus to bulk compressibility (case study). Egyptian Journal of Petroleum, 24(2), 113-118.

Lacy, L. L., 1997. Dynamic rock mechanics testing for optimized fracture designs. SPE Annual Technical Conference and Exhibition.

Najibi, A. R., Ghafoori, M., Lashkaripour, G. R., \& Asef, M. R., 2015. Empirical relations between strength and static and dynamic elastic properties of Asmari and Sarvak limestones, two main oil reservoirs in Iran. Journal of Petroleum Science and Engineering, 126, 78-82.

Ryshkewitch, E., 1953. Compression strength of porous sintered alumina and zirconia: 9th communication to ceramography. Journal of the American Ceramic Society, 36(2), 65-68.

Sethi, D. K., 1981. Well log applications in rock mechanics. SPE/DOE Low Permeability Gas Reservoirs Symposium.

Tixier, M. P., Loveless, G. W., \& Anderson, R. A., 1975. Estimation of formation strength from the mechanicalproperties log. JPT, Journal of Petroleum Technology, 27, 283-293.

Weingarten, J. S., \& Perkins, T. K., 1995. Prediction of sand production in gas wells: methods and Gulf of Mexico case studies. Journal of Petroleum Technology, 47(07), 596-600.

Woehrl, B., Wessling, S., Bartetzko, A., Pei, J., \& Renner, J., 2010. Comparison of methods to derive rock mechanical properties from formation evaluation logs. 44th US Rock Mechanics Symposium and 5th USCanada Rock Mechanics Symposium.

Wu, B., Bahri, C., Tan, C., Li, Q., Abd Rahim, M. H., Kartoatmodjo, G. P., \& Friedel, T., 2010. Sand production prediction for a mature oil field-a case study. SPE Asia Pacific Oil and Gas Conference and Exhibition.

Zhang, J. J., 2019. Applied petroleum geomechanics. In Applied Petroleum Geomechanics.

Zhang, S., \& Abdelrahman, I. M., 2015. Correlation of rock mechanic properties with wireline log porosities through fulla oilfield-mugllad basin-sudan. SPE North Africa Technical Conference and Exhibition.

Zoback, M. D., 2007. Reservoir geomechanics. Cambridge University Press. 